\title{
Depois que Papai e Mamãe se Separaram: um Relato dos Filhos ${ }^{1}$
}

\author{
Rosane Mantilla de Souza ${ }^{2}$ \\ Pontifícia Universidade Católica de São Paulo
}

\begin{abstract}
RESUMO - O objetivo deste trabalho foi compreender como os filhos vivenciam a separação dos pais: se identificam a tensão antecedente a separação, como compreendem e reagem a ela e suas conseqüências e quais as fontes de apoio percebidas por eles. Tratou-se de uma pesquisa qualitativa, realizada através de entrevistas com 15 adolescentes de ambos os sexos, que tinham entre quatro e 11 anos quando os pais se separaram. Os filhos podem ou não perceber a tensão familiar pré-separação, mas, independente disso, suas maiores dificuldades e fontes de sofrimento referem-se à saída de casa de uma das figuras parentais e à falta de previsibilidade dos eventos da vida cotidiana, conseqüentes à separação dos pais. Apesar de relatarem solidão, isolamento e ausência ou incapacidade de encontrar fontes de apoio, todos afirmaram que o divórcio foi uma boa solução para a família. Importantes aspectos de tensão e estresse infantis poderiam ser evitados através de ações de promoção de saúde, grupos de apoio e orientação dos pais.
\end{abstract}

Palavras-chave: crianças; adolescentes; família; divórcio; estudo qualitativo.

\section{After Daddy and Mom Divorced: A Children's Report}

\begin{abstract}
The aim of this work was to understand how children experience parents' divorce: if they identify tensions before separation, how they comprehend and react to it and its consequences, and the what is the support they rely on. Data were collected through interviews and analysed by means of qualitative methodology. Subjects were 15 adolescents, both sexes, aged between 4- and 11-years-old when divorce occurred. The results showed they may or may not grasp family tension before separation but, apart from that, their main difficulties and sources of distress are related to one of the parents leaving home and the subsequent lack of previsibility for daily life events. In spite of reporting feelings of loneliness, isolation and lack or difficulty to find sources of support, all of them affirmed that divorce was a good solution for the family. Important aspects related to tensions and stress could be avoided with actions for health promotion, support groups and counselling for parents.
\end{abstract}

Key words: children; adolescents; divorce; family; qualitative analysis.

Desde que o divórcio se tornou cada vez mais freqüente, acumulou-se uma considerável literatura mundial a respeito do ajustamento infantil, contando-se hoje, com boas revisões bibliográficas que permitem concluir que as pesquisas das décadas de 1960 e 1970 superestimaram os efeitos deletérios do divórcio per se (Amato, 1994, 1995; Hetherington \& Stanley-Hagan, 1999; Kelly, 1998; Lamb, Sternberg \& Thompson, 1997).

As crianças tem sua saúde mental associada ao bem estar dos pais e à qualidade do relacionamento entre ambos. Assim, estarão sob risco, quando crescerem numa família onde o casal esteja em conflito, quer vivam juntos ou não. Por outro lado, os filhos de divorciados poderão ser competentes e bem ajustados quando o divórcio puder conter a escalada de conflitos entre os cônjuges e a mãe ou pai que estiver com a guarda das crianças for capaz de proporcionar um ambiente de cuidado positivo, a despeito do estresse inerente ao seu papel singular mais sobrecarregado (Hetherington \& Stanley-Hagan, 1999).

1 A autora agradece a colaboração das alunas do curso de Psicologia da PUC-SP, Marina Amadeu Bragante e Viviane Palma Lopes, bolsistas de Iniciação Científica-CNPq.

2 Endereço: Rua Apinagés, 1752, Apto. 24, Perdizes, São Paulo-SP, CEP 01258-000. Email: rosane@ pucsp.br
O divórcio, mais que um evento isolado, é um longo e complexo processo, envolvendo múltiplas mudanças. Até o presente, os autores, em geral, remetem-se ao estudo de Hetherington, Cox e Cox (1982), que verificou a decorrência de um período de cerca de quatro anos, a partir da separação, até que todos os ajustamentos familiares necessários tenham ocorrido. As adaptações infantis, consideradas sob uma perspectiva temporal, dependem, por um lado, da quantidade e qualidade do contato com a figura parental não detentora da guarda e, por outro, do ajustamento psicológico e da capacidade de cuidado da figura parental detentora da guarda, do nível de conflito entre os pais após a separação ou o divórcio, do nível de dificuldades sócio-econômicas e do número de eventos estressores adicionais que incidiram sobre a vida familiar (Amato, 1994, 1995; Lamb \& cols., 1997; McConnel \& Sim, 1999; Schwartz, 1992).

Dar condições para que o divórcio se torne um instrumento de solução para as dificuldades e conflitos do casal tem redundado no uso cada vez mais freqüente da mediação conjugal, quer pela busca espontânea dos casais em processo de separação, quer como parte obrigatória dos processos de divórcio em muitas das varas de família nos Estados Unidos, Canadá, França e Austrália, por exemplo. Também tem se tornado cada vez mais divulgados e utilizados os trabalhos de orientação e grupos de apoio, tanto para os adultos quanto para as crianças envolvidas (Emery, Kitzmann \& Waldron, 1999). 
O divórcio é assunto particularmente explorado em publicações norte-americanas e nelas predominam, ainda, os estudos quantitativos. Ao identificar as poucas informações sobre a experiência dos próprios sujeitos, Hetherington e Stanley-Hagan (1999) afirmam que, a despeito de sua preferência por métodos quantitativos: a compreensão da experiência e dos sentimentos dos pais divorciados e seus filhos precisa ser aprimorada através do uso de métodos qualitativos (p. 137). Estas informações qualitativas sobre a vivência e sobre as diferentes necessidades de todos os envolvidos, identificando as demandas a partir de suas próprias perspectivas, são fundamentais não só para o psicoterapeuta, mas também para todos os interessados em organizar projetos de promoção de saúde, que favoreçam uma transição menos traumática para os diferentes subsistemas familiares envolvidos na separação conjugal.

Particularmente, no que se refere às crianças, alguns temas de experiência têm sido identificados. Por exemplo, o estudo de Fry (1983) discute as percepções, sentimentos e preocupações de 132 meninos e meninas canadenses de oito a 11 anos de idade, dois anos após a separação conjugal. Comparando guarda materna e paterna, o autor aponta que as crianças que vivem com a mãe, comparadas às que vivem com o pai, tendem a descrevê-las como tendo mais dificuldade para lidar com problemas financeiros, cansadas, deprimidas, desprotegidas e sem condições de ajudar os filhos em suas interações com amigos, mas, ao mesmo tempo, com maior capacidade que os pais para cuidar deles quando estão doentes ou com dificuldades. As mães também são descritas como mais disponíveis e os pais como mais distantes. As crianças de ambos os grupos relataram, ainda, o medo e a ansiedade em relação à experiência familiar, no sentido de ter as suas necessidades atendidas. Preocupavam-se com o sucesso profissional de ambos os pais, mas principalmente da mãe, demonstrando grande preocupação com o futuro.

Ducibella (1995) alerta para a escassez de pesquisas sobre a forma como os pais informam à criança a respeito do divórcio. Segundo sua revisão de estudos sobre o tema, o tipo de explicação fornecida, o momento escolhido para dar a informação e quem são os informantes podem estar associados ao locus de controle (o quanto a criança acredita que controla a própria vida versus em que extensão acha que fatores externos a controlam), ao medo de ser abandonada, às reações emocionais iniciais e à tendência de tomar partido. Para o autor, o cenário que emana dos relatos analisados é que a notícia é dada pela mãe, sozinha e claramente infeliz.

Um dos trabalhos que focaliza mais exaustivamente o ponto de vista das crianças e adolescentes é o de Wadsby e Svedin (1994), realizado na Suécia, que compara a percepção de 32 sujeitos de sete a 18 anos e seus familiares, dois anos após o divórcio. A pesquisa aponta que metade das crianças e dois terços dos adolescentes identificam o conflito parental e pressentem que o divórcio irá acontecer. Além disso, informam que $44 \%$ dos filhos não desejam que seus pais se reunam novamente, se o preço for a perpetua- ção do conflito, e outros $16 \%$ têm certeza de que seus pais devam permanecer separados. Para a maioria dos filhos, a escolha não era viver em uma família nuclear ou divorciada, e sim viver numa família com ou sem conflitos. O desejo de reconciliação aparecia apenas entre aqueles que tinham contato raro ou inexistente com a figura parental não residencial, quer fosse o pai ou a mãe. Os autores relatam, ainda, uma falta de comunicação entre pais e filhos decorrente do processo de separação, verificado, também, por Wallerstein e Kelly (1980) no que se refere, principalmente, a haver, entre os pais, a idéia de que falar sobre o divórcio perturba as crianças. Assim, os pais não tocam no assunto da separação. Os filhos os complementam e, por conseqüência, mantêm seus sentimentos escondidos. O silêncio é entendido pelos pais como indício de ausência de dificuldades.

Em 1984, registraram-se no Brasil 30.847 sentenças de divórcio em primeira instância, 56\% das quais envolvendo filhos menores, e, em 1994, estes números já estavam na ordem de 98.766 divórcios, $65 \%$ envolvendo menores. No entanto, apesar desses índices, as pesquisas brasileiras são raras, principalmente aquelas que descrevem a experiência dos próprios filhos.

Bucher (conforme citado por Ribeiro, 1989), ao estudar a percepção da separação por parte dos filhos, descreveu que mais da metade dos seus sujeitos de oito a 16 anos se posicionavam contra o divórcio, $11 \%$ eram indiferentes e $32 \%$ favoráveis. Segundo a autora, o tratamento dado aos filhos interfere em sua aceitação ou rejeição à separação e a investigação mostrou que a atitude predominante do pai foi de ignorar os filhos e a da mãe de aceitação.

Ribeiro (1989) analisou quais foram as consequiências positivas e negativas percebidas por um grupo de 23 adolescentes de cerca de 13 anos, residentes na cidade de Brasília. Os sentimentos descritos quanto a separação foram de tristeza, alívio e aceitação. O final do conflito parental foi percebido como o principal aspecto positivo da separação por 21,5\% dos adolescentes, embora $26,1 \%$ deles não mencionaram qualquer efeito positivo. As conseqüências negativas emergiram em menor escala ainda: $39,1 \%$ do grupo considerou que nada desagradável tinha ocorrido, outros descreveram a ausência paterna $(17,4 \%)$, mudanças na estrutura de vida (presença de padrasto, mudança de casa, de escola) e, ainda, outros apontaram dificuldades pessoais dos pais (tristeza, beber).

Embora tenham objetivos um pouco diferentes do que a identificação de temáticas de experiência, cabe mencionar também a produção de Wagner, Falcke e Meza (1997), que traz informações acerca dos adolescentes e suas famílias, no Brasil. Wagner e cols. buscaram caracterizar as crenças e valores de adolescentes acerca de "família", "casamento", "separação" e "projetos de vida", através do uso de "frases incompletas" sobre estes temas, aplicadas a 60 jovens entre 12 e 17 anos, metade proveniente de famílias em seu primeiro casamento e metade recasadas. Segundo as autoras, especificamente em relação a casamento e separação, foram verificadas diferenças significativas comparando-se 
os sexos. As meninas acreditam que as pessoas se casam porque se amam (97\%) e se separam porque deixam de se amar $(56,25 \%)$, enquanto os meninos atribuem causas mais diversificadas para o casamento, pensando que a separação ocorre porque os casais "não se acertam".

Wagner e Sarriera (1999) analisaram o perfil diferenciador das relações que se estabelecem entre os adolescentes e as figuras parentais e os cônjuges de segundos casamentos, através do uso do "Inventário sobre Rede de Relações Interpessoais”. Este instrumento foi aplicado em 394 adolescentes entre 12 e 17 anos de idade, metade filhos de pais divorciados e casados pela segunda vez e metade de famílias em primeira união conjugal. Deste estudo, cabe destacar um relacionamento mais próximo, mais intenso e solidário com os irmãos, entre os jovens que viveram o divórcio parental, e uma correlação positiva entre as relações mãe-madrasta, pai-padrasto e o relacionamento dos filhos com os novos cônjuges, indicando que a relação satisfatória com os pais permite ao jovem sentir-se mais seguro no relacionamento com os novos parceiros.

Finalmente, alguns outros temas podem ser destacados, a partir da pesquisa que realizamos, buscando compreender a perspectiva infantil das transformações familiares, particularmente as introduzidas pelo divórcio (Souza, 1998, 1999). Participaram do estudo 61 crianças paulistas de cinco a 11 anos, um terço das quais provenientes de famílias divorciadas. Foi possível identificar que a separação era entendida como uma certeza por todas as crianças, no caso de relacionamentos conflituosos ou quando "acabava o amor", o mesmo encontrado por Wagner e cols. (1997), embora sem as diferenças de sexo observadas por estes últimos.

Independente da idade, ou de ter vivido o divórcio dos pais, todas as crianças consideravam a tristeza, a mágoa, a sensação de abandono, a solidão e a saudade como os sentimentos preponderantes quando da separação, semelhante ao encontrado no estudo de Ribeiro (1989). No entanto, as crianças insistiam em mencionar que estes sentimentos modificavam-se ao longo do tempo, principalmente quando havia a redução do conflito conjugal. Embora a separação fosse entendida como fonte de grande sofrimento, as crianças mostravam-se capazes de diferenciar sua experiência em relação aos afetos parentais, descrevendo um processo de ajustamento e mudança de sentimentos ao longo do tempo, o que incluía o relacionamento com os novos parceiros parentais. Particularmente as mais velhas (10 e 11 anos), que haviam vivido o divórcio e, ocasionalmente, novas uniões parentais, mencionavam que os pais podiam ficar mais felizes com o passar do tempo, o que redundava num clima familiar de melhor qualidade e em uma melhora no cuidado para com elas.

Portanto, as informações obtidas através destas investigações não se contrapõem. Ao contrário, complementamse, deixando visualizar um quadro onde o conflito parental é central e o tipo de comunicação, bem como a adequação das informações e condutas parentais, talvez possam minimizar o sofrimento infantil. Assim, o presente trabalho foi organizado como uma pesquisa qualitativa, com o objetivo de in- vestigar como os filhos de pais divorciados vivenciaram o processo de separação e suas principais acomodações após um período de cerca de quatro anos. Buscou-se, então, compreender: (a) se os filhos identificaram a tensão e o conflito pré-separação, (b) como compreenderam e reagiram à separação conjugal, (c) como viveram o processo de adaptação à separação e (d) quais os recursos e apoios utilizados para enfrentar os vários momentos do processo.

\section{Método}

\section{Participantes}

Participaram do estudo 15 adolescentes, sete de sexo masculino e oito de sexo feminino, com idades entre $14 \mathrm{e}$ 18 anos. Todos haviam vivido a separação conjugal na infância, sete quando tinham entre quatro e oito anos e os demais entre nove e 11 anos de idade. O tempo mínimo de separação era de quatro anos e o máximo de 11 anos. Todos os pais já haviam se divorciado: quatro das mães eram casadas novamente e outras quatro tinham relacionamentos descritos como duradouros, embora não houvesse moradia comum com o novo parceiro. Entre os pais, sete haviam se casado, um mantinha um relacionamento duradouro sem co-habitação e um havia falecido. Apenas dois dos adolescentes viviam uma situação em que tanto o pai quanto a mãe tinham novos cônjuges. Finalmente, quanto a irmãos, dois eram filhos únicos e, dos treze restantes, oito tinham irmãos com mais de oito anos quando da separação, seis tinham irmãos com menos de seis anos e dois tinham irmãos com mais e com menos de oito anos.

\section{Procedimento}

Foram realizadas entrevistas individuais semi-dirigidas. Solicitou-se, inicialmente, que os jovens relatassem o que lembravam da época da separação parental e como as coisas foram mudando. Não havia um roteiro prévio, nem questões previamente formuladas, deixando-se o participante livre para descrever sua vivência. Foram feitas questões de esclarecimento e introduzidos tópicos específicos de experiência, apoiados nas informações da literatura, à medida que havia abertura no depoimento. Ao final, quando necessário, foram feitas perguntas específicas.

Além do conteúdo espontâneo dos relatos, as entrevistas buscaram informações sobre: (a) dados de identificação pessoal e familiar; (b) como foi a separação dos pais (se percebia alguma coisa, conflitos, se desconfiava que alguma coisa estava acontecendo, conversava/perguntava); (c) como ficou a vida imediatamente após a separação (informações que recebeu, sentimentos, mudanças, relacionamentos com mãe, pai, avós maternos e paternos e outros familiares, amigos próprios e dos pais); (d) dificuldades e aspectos positivos (para si e para os outros, fontes de apoio); (e) como, e no que as coisas mudaram com o tempo (o que interferiu na mudança, apoios encontrados); (f) novos parceiros e novas famílias. 
As entrevistas ocorreram em ambiente neutro, sem interrupções externas e foram realizadas em um único encontro que durou de uma a três horas. Todas as entrevistas foram gravadas, sob autorização, e transcritas. Foram identificados os temas de experiência, buscando-se caracterizar toda a gama de vivências descritas, segundo a lógica proposta pelos entrevistados.

\section{Resultados e Discussão}

\section{A separação dos pais}

Todos os entrevistados afirmaram lembrar, com clareza, o período de tempo ao redor da separação e da saída de casa de um dos membros do casal, embora este fato tenha ocorrido em idade precoce para muitos dos envolvidos. Dentre todos eles, apenas uma das meninas vive, e sempre viveu, numa família com guarda paterna; todos os demais estão sob a guarda materna. Três dessas últimas foram morar com a mãe, na casa dos avós maternos, e numa dessas casas também morava uma das irmãs da mãe (tia materna).

Dez participantes descreveram ter percebido que algo não ia bem em casa na época da separação e, dentre eles, estavam quatro, dos seis, que tinham menos de seis anos de idade naquele momento. Os outros cinco entrevistados disseram que, naquele época, não identificaram nada, mas que ao longo do tempo passaram a perceber o conflito e a tensão conjugal e familiar. Pensando sobre isso, muitos lembraram:

\begin{abstract}
As coisas não iam bem. Minha mãe chorava muito e meu pai nunca estava em casa. (Fem., 8 anos quando da separação.)

Eles brigavam muito. Eu e o meu irmão nos escondíamos no quarto da empregada.(Masc., 6 anos quando da separação.)

Minha mãe me mandava para o quarto e eu ficava brincando e eles gritavam. (Masc., 9 anos quando da separação.)

Eu quase não via meu pai. No fim de semana eu via ele dormindo no escritório. Eles não se falavam. (Fem., 10 anos quando da separação.)
\end{abstract}

Nossos resultados se assemelham aos de Wadsby e Svedin (1994), no que diz respeito à identificação do conflito conjugal por parte dos filhos, mas nossas entrevistas permitiram perceber que existe uma diferença entre identificar o clima tenso e o conflito conjugal e associá-los à possibilidade de separação. Assim, foram descritas duas categorias: identificação do conflito $(n=10)$ e não identificação do conflito $(n=5)$. A identificação do conflito era acompanhada pela (a) percepção de tristeza dos pais, sem compreensão de sua seriedade; (b) antecipação da separação; (c) envolvimento, sem perceber a gravidade das consequiências. Já, a não identificação do conflito era acompanhada por relatos de (a) surpresa, achar engraçado e (b) não se lembrar, não ter sido um fato marcante na época.

Apenas três entrevistados anteciparam uma possível separação conjugal, sendo que apenas um deles pertencia ao grupo dos "mais velhos". Os sete outros, que identificaram o conflito conjugal, relataram que a experiência mais mar- cante estava relacionada à não compreensão do que estava acontecendo e ao não estabelecimento de uma ligação causal entre conflito declarado, ou encoberto, e a possibilidade de uma separação. No entanto, todos relataram que, com o correr do tempo, foram estabelecendo a relação entre conflito e separação, embora isto não tivesse ocorrido imediatamente: foi tudo uma coisa demorada, de ir juntando pedaços; demorou bastante tempo, procurando entender, pensar uma coisa, depois outra. E, mesmo os que não identificaram o conflito ou não avaliaram sua seriedade, afirmaram que, posteriormente, podiam perceber como a situação familiar era tensa e o conflito encoberto.

A saída do pai de casa e as informações que a criança recebe aparecem como um fato marcante que deve ser considerado nos trabalhos de orientação de pais, conforme apontou Ducibella (1995). Entre os participantes, três relataram não se lembrar como ou mesmo se foram informados, enquanto outros três contaram que foram deixados a si mesmos para tirar conclusões, como pode ser observado no relato desta menina que na época tinha oito anos:

Eu lembro que eles brigavam muito e que nos sábados a gente
ficava debaixo de uma guerra. Ai, num sábado meu pai levou
eu e a minha irmã para ver um monte de apartamentos, ele
perguntava se nós gostávamos ou não. Foram umas três ou
quatro semanas assim. Eai, ele foi embora. Ele não disse nada,
minha mãe também não, nem eu nem minha irmã pergunta-
mos nada. Ai ele nos levou um fim de semana para a casa
'dele' e quando ele me levou de volta para a casa da 'minha
mãe' eu comecei a entender o que estava rolando. (O grifo é
nosso e busca dar a idéia do tom e gesticulação usados para
ressaltar os sentimentos envolvidos.)

Outros dois contaram que foram informados pela mãe, após irem buscar explicações do que estava acontecendo, como é o caso deste menino que tinha nove anos na época:

Eu achava que vivíamos bem em casa. Não percebia nada de errado e nem desconfiava do que estava para acontecer. Meu pai não foi dormir em casa num dia e minha mãe falou que estava trabalhando. No dia seguinte ele não foi novamente e eu perguntei, forcei a barra mesmo, e então ela falou que seria assim desse dia em diante, que eles estavam separados porque não se amavam mais e que eu iria ter que me adaptar. Acho que foi pior assim. Se eu ao menos desconfiasse, não teria sofrido tanto. $O$ impacto foi muito grande...

Os outros sete entrevistados contaram que foram informados por ambos os pais. Os relatos são bastante semelhantes, tendo em comum a descrição da atitude solene dos mesmos, a presença de todos os irmãos, o clima de tensão, a insistência de que estavam se desentendendo muito e que essa era a melhor solução. Além disso, ambos os pais insistiam em dizer que a separação não tinha relação com os filhos e que eles não deixariam de ser amados. O depoimento abaixo resume a experiência de todos:

A gente sentou no sofá, um perto do outro. Meu irmão deu um chute na minha irmã e minha mãe olhou para os dois, e meu pai 
também, mas eles não falaram nada, e ficou de repente tudo quieto. Eu comecei a achar (silêncio) tinha acontecido alguma coisa, mas eu não sabia o quê. Aí eu comecei a olhar para o meu tênis, ele tava sujo e tinha um rasgão... eu tava assustada e meus irmãos também, porque eles estavam quietos do meu lado e meu irmão encostou em mim. Os dois (pais) falaram ao mesmo tempo que tinham uma coisa importante para dizer para nós. Eles olharam um para o outro e minha mãe falou que ela gostava muito da gente. Meu pai falou que ele também. Eu sabia que estava acontecendo alguma coisa pela cara deles, mas acho que eu não pensava o que era.... Meu cachorro chegou perto e meu pai começou a passar a mão nele... puxava o pelo do Tobi que ele ganiu. A minha mãe ficou brava. Eles se olharam fuzilando e meu coração disparou. Aí ele falou que eles estavam com problemas um com o outro, que não era por nossa causa, que eles não iam deixar de gostar da gente mas que eles iam se separar. Aí ela falou que a vida da gente não ia mudar porque eles nos amavam muito, era só que meu pai ia morar em outra casa... Acho que nós três olhávamos para o chão e fazíamos força para não chorar.. Ficou silêncio. Minha irmã gritou que ela queria ir no banheiro e nós saímos os três da sala. A gente foi para o quarto meu e dai minha irmã e meu irmão falou se podia ficar com a gente. Sabe, de repente eu sentia que só tinha nós três, a gente não falou nada e eu deitei na minha cama e o Tobi deitou comigo. Meu irmão ficou parado de pé e ai a minha irmã falou para ele," vem fica aqui comigo" e ela abraçou ele e nós ficamos quietos... (Quantos anos vocês tinham ?) Eu era a mais velha eu tinha onze, minha irmã tinha oito e meu irmão tinha seis.

Entre a conversa sobre a separação e a saída do pai de casa, ou a percepção de sua ausência e a conclusão sobre a separação, decorre um período de tempo de cerca de um mês, segundo os depoimentos. Os entrevistados que receberam informações dos pais, em conjunto, afirmaram que, neste período, sentiam-se assustados e algo como entorpecidos. Todas estas crianças tinham irmãos, tanto mais velhos quanto mais novos (com idades entre dois e 12 anos) e disseram que eles e seus irmãos não choraram, ou que choraram escondido, e ficaram mais juntos e sem muita briga. O clima da casa era tenso e não se conversava sobre o que estava acontecendo. Esta maior coesão do subsistema fraterno nos remete ao observado entre os jovens de famílias recasadas, descrito por Wagner e Sarriera (1999), sugerindo a necessidade de mais investigações sobre estas relações, pois se, ao mesmo tempo, é relatada uma aproximação, também é referido um bloqueio de comunicação. De fato, apenas dois dos participantes afirmaram ter falado com seus irmãos sobre as impressões ou sentimentos daqueles dias, em qualquer outro momento de suas vidas.

A consciência da ausência paterna materializa a separação sendo apontada por todos como o momento onde preponderam os "piores sentimentos". Todos referiram-se ao grande sofrimento em relação à separação dos pais, mesmo reconhecendo, em retrospectiva, que a separação foi uma solução. Os sentimentos descritos foram de tristeza, medo, medo do que iria acontecer, angústia, fechamento e raiva, assinalando a condição de desamparo das crianças, conforme descrito em trabalhos anteriores (Ribeiro, 1989; Souza, 1999).

Como enfatizado por Ducibella (1995) e Wadsby e Svedin (1994), as informações obtidas diretamente do casal, em con- junto, parecem favorecer que a criança sinta-se menos envolvida na separação ou possa mobilizar mecanismos de defesa e estratégias de enfrentamento para lidar com a crise. Todos os entrevistados relataram sentimentos de perda e comportamentos reativos, embora aqueles que foram informados sobre a separação por ambos os pais não se referiram a sentimentos de culpa pela separação, nem a tentativas de reunião dos mesmos. Os demais afirmaram ter negado o que estava ocorrendo, por meses: o louco não é que eu não dizia para ninguém que meu pai tinha ido embora, é que eu acreditava, para mim mesmo, que ele estava viajando. Acho que meus irmãos também. Ninguém falava nada em casa. (Masc., 10 anos quando da separação.)

Dois outros entrevistados disseram que demoraram cerca de um a três anos para achar que seus pais iriam mesmo ficar separados, alimentando a idéia de que a situação poderia ser reversível: porque eles se davam tão bem depois de separar... só quando meu pai apareceu com a namorada é que eu comecei a achar que era mesmo verdade e ai eu fiquei com muita raiva. (Masc., 6 anos quando da separação.)

Se, através dos relatos é possível entender que uma informação clara, dada por ambos os pais, favorece compreender que de fato houve ou haverá uma separação, ajudando a criança a se diferenciar do conflito conjugal, a falta de explicações sobre o que ocorrerá com sua vida dali para frente parece ser um dos temas de grande dificuldade e sofrimento infantil. Todos os entrevistados descreveram a falta de esclarecimentos acerca das conseqüências práticas da situação como algo muito difícil de enfrentar e o que os tornava ainda mais confusos e impotentes sobre o total dos acontecimentos. Segundo eles, embora os pais tenham comunicado que iriam se separar, porque não estavam se dando bem ou porque não se amavam mais, era difícil compreender o que isto significava na prática e na rotina de vida.

\section{O período imediatamente após a separação}

Quando as crianças contaram como foram os momentos imediatos após a separação e suas primeiras conseqüências, os relatos começavam, sempre, descrevendo a confusão, a angústia e a raiva associada às mudanças na rotina de vida e pouca previsibilidade ambiental e, em segundo lugar, as mudanças nos relacionamentos. Foram referidas como mudanças na vida: mudança de moradia $(n=8)$, mudança de cidade $(n=1)$, alterações de padrão econômico $(n=2)$, mudança de escola $(n=2)$, passar a usar transporte escolar ou sair dele $(n=2)$, mudança da rotina diária pelo fato de a mãe começar a trabalhar $(n=2)$.

É possível perceber que estas mudanças estão associadas e, assim, muitas delas incidem, ao mesmo tempo, sobre a mesma criança e têm, como conseqüência, alterações significativas nas redes de relacionamento familiar e de amizade. As mudanças iniciais relatadas nos relacionamentos foram:

1. Mudanças no relacionamento com o pai e/ou redução de contato com o mesmo $(n=8)$.

Antes, eu esperava meu pai prá jantar, mesmo quando 
eles já tavam bravos um com o outro e ai, de repente, ele foi embora. Ele telefonava todo dia, mas não era igual. (Fem., 10 anos quando da separação.)

2. Mudanças no relacionamento com a mãe $(n=4)$. Minha mãe um dia chorava, noutro dia tava histérica, noutro estava alegrinha, mas de fato aonde pegava é que eu sentia que era eu, eu, que tinha que cuidar dela. Ela tava frágil. (Masc., 9 anos quando da separação.)

3. Mudanças no relacionamento com irmãos $(n=3)$

Eu e minha irmã brigávamos o tempo todo, quer dizer, quando estávamos juntas, porque eu estudava de tarde e ela de manhã. Aí, mudamos de escola e íamos juntas, no mesmo horário e chegava em casa ficávamos um pouco sozinhas (...) mas sabe que ai paramos de brigar e começamos a brincar juntas, fazer lição juntas. (Fem., 11 anos quando da separação.)

4. Aproximação da família materna $(n=2)$

Víamos pouco meus avós e aí, de repente, eles vinham visitar a gente quase todos os dias. No começo foi legal mas depois minha avó começou a palpitar em tudo e ela brigava com a minha mãe, caos total! Mesmo assim eu gostava porque ela me paparicava e fazia tudo para mim. (Masc., 6 anos quando da separação.)

5. Afastamento da família paterna $(n=2)$

Foi uma barra. Todo o fim de semana a gente ia na casa da mãe do meu pai, mesmo quando ele tava viajando e, de repente, minha mãe não levava mais e chegou um tempo em que eu fiquei um tempão (?) acho que sei lá, três, quatro meses, sem ver ela, só telefonando, era de quem eu mais sentia saudades, mais que do meu pai. (Masc., 9 anos quando da separação.)

6. Afastamento de amigos do pai ou da mãe $(n=4)$

Todo o fim de semana a gente ia para a casa da tia Silvia e do tio Pedro e ai, de repente, acabou. Mesmo meu pai, que era amigo deles, não levava e gente lá quando a gente tava com ele nos sábados. (Masc., 6 anos quando da separação.)

7. Perda de amigos $(n=4)$

Mudei de escola, mudei de casa. Eu tinha um montão de amigas, então, micou tudo, enfiada dentro de casa e minha mãe ainda reclamando que eu ficava o tempo todo jogando video game, acredita?! (Fem., 10 anos quando da separação.)

O número de mudanças descritas mostra o quanto a situação envolve perdas múltiplas. A criança acaba tendo que enfrentar não só as modificações da estrutura e funcionamento familiar, mas também tem que enfrentar alterações profundas em sua rotina de vida, o que, por si só, é extremamente doloroso. O número e diversidade das mudanças relatadas apontam para a quantidade de estresse envolvido, o qual requer das crianças um número tal de adaptações que dificilmente poderiam ser enfrentadas, mesmo por um adulto.

\section{Algumas dificuldades e aspectos positivos da separação}

Não informados sobre o que se modificará em suas vidas e, talvez, assegurados pelos pais de que nada mudará, apenas o papai vai morar em outra casa, os filhos ficam confusos e não buscam informações, reproduzindo o que já fora observado por Wadsby e Svedin (1994) e Wallerstein e Kelly (1980), isto é, as crianças não perguntam e os pais concluem que está tudo bem. Com a rede social esgarçada, confusos e tentando proteger os pais, elas acabam comunicando o sofrimento através de sintomas. Os participantes, espontaneamente, descreveram um conjunto de reações por eles associadas à eclosão da separação, discriminado um grande número de dificuldades psicossociais relativas ao período inicial como: dificuldades e perturbações de sono, pesadelos $(n=3)$; problemas de alimentação (comer muito ou quase não se alimentar, vomitar) $(n=3)$; enurese $(n=$ 2 ); comportamentos regressivos (chupar dedo, roer unha, tomar mamadeira) $(n=2)$; choro excessivo $(n=2)$; medo e ansiedade difusa $(n=2)$; medos definidos como de ficar sozinho, sair sozinho $(n=2)$; mau humor e agressividade $(n=3)$; sentimentos de culpa $(\mathrm{n}=2)$; sensação de abandono e de falta de alguém a quem recorrer $(n=2)$; rebaixamento do desempenho escolar $(n=2)$.

Os entrevistados acreditam que suas dificuldades não foram percebidas, ou talvez tenha sido difícil conceber que os pais e demais familiares fossem capazes de responder às suas necessidades, como foi sugerido por Fry (1983), cujo estudo aprofunda exatamente a percepção dos primeiros dois anos de separação. Embora seis participantes tenham comentado que conversaram com alguém (ex.: amigo, irmã, tia e professora), a respeito do conflito conjugal pré-separação, todos negaram que falassem sobre seus sentimentos ou dúvidas a qualquer pessoa, durante o primeiro período que envolveu a separação propriamente dita.

As mudanças no relacionamento com pai e mãe foram as que mais incidiram sobre os envolvidos e a comunicação com eles foi descrita como totalmente bloqueada. Quatro crianças comentaram não ter falado nada porque se preocupavam com o sofrimento materno $(n=2)$ ou paterno $(n=2)$. $\mathrm{O}$ aumento da tensão no relacionamento com o genitor residencial $(n=3)$ e o distanciamento de relacionamento com ambos os genitores também foram mencionados $(n=$ 3). A ausência de comunicação, acrescida da tensão relativa às mudanças, e a dificuldade ou impossibilidade de encontrar apoio, redundavam numa descrição unânime de solidão. A separação propriamente dita foi descrita como: um momento de muita bagunça $(n=3)$; momento sofrido, chato, confuso $(n=6)$; período de redução da agressividade e do confronto anterior $(n=3)$; momento de sentimentos ambivalentes $(n=3)$; momento de extrema dificuldade por causa das mudanças materiais e de relacionamento $(n=10)$.

Todos consideraram que, com o passar do tempo, com a fixação de um sistema de visitas e o estabelecimento e/ou desenvolvimento de confiança na previsibilidade das novas rotinas, o impacto emocional cedeu lugar a novas adaptações. A maioria dos entrevistados não conseguiu precisar um período de tempo transcorrido para que as primeiras adaptações tivessem lugar. Contaram apenas que foram compreendendo como as coisas iriam ficar e, com isso, a ansiedade foi se reduzindo. A previsibilidade da vida e a 
adaptação às mudanças concretas como moradia, escola, novos amigos foram descritas como se processando durante um período de seis meses a um ano, segundo a descrição de cinco dos participantes que conseguiram dar alguma informação. As relações familiares assumiram papel de destaque.

Morar com os avós, embora à primeira vista possa aprofundar vínculos e fornecer fontes de apoio, não foi assim concebida pelos que viveram a situação $(n=2)$ :

Ficou horrivel. Não foi por causa da casa em si, tinha tudo e eu tinha um quarto com minhas coisas, TV, brinquedos. É que minha avó falava mal do meu pai o tempo todo e queria que eu contasse para ela como era na casa dele. Quando ele telefonava, ela mandava eu ir logo... Antes eu adorava ficar lá, aí ficou um inferno. (Masc., 10 anos quando da separação.)

Dois dos meninos afirmaram que seu contato com o pai aprofundou-se, cabendo, no caso, acrescentar que estes entrevistados referiram-se ao extremo conflito entre os pais:

Eu comecei a sair com ele e ia na casa dele. Era um ap (sic) bem pequeno e não tinha quase nada. A gente via TV, eu levava um jogo, depois eu levei o video game. A gente saia pouco e meu pai cozinhava - ele cozinha bem prá caramba - e ele parecia outro. Hoje eu vejo como a vida deles era ruim e como a separação foi boa para todos nós. Minha mãe também começou a pegar mais leve comigo e ficou mais feliz. também. Com o tempo eles ficaram assim, tipo amigos, quer dizer não brigam, ficam juntos nas festas de aniversário numa boa, conversam, resolvem as coisas minhas juntos, como outro dia. de deixar eu ir viajar. Às vezes eu vejo uns amigos meus que o pai sumiu, ou que os pais continuam brigando e vejo como minha vida é boa. Era péssimo porque eles gritavam, choravam o tempo todo e nunca concordavam com nada. Eles concordam tanto que nem dá prá eu dar umas aproveitadas e jogar um contra o outro. Não, não... é brincadeira!" (Masc., 10 anos quando da separação.)

Mesmo durante este processo de adaptação posterior, a solidão, a sensação de falta de apoio e fechamento em si mesmo estiveram bastante presentes. Sete dos entrevistados disseram que não conversavam com ninguém. Dois justificaram que ninguém parecia preocupado com ele e outro afirmou que a superproteção da família materna aumentava sua sensação de confusão, fazendo com que se fechasse em si mesmo ainda mais. Outros quatro, todos com irmãos com mais de oito anos de idade, disseram que não falavam nem mesmo com os irmãos que também viviam o processo $(n=4)$.

Em contrapartida, os outros oito participantes, ressaltaram a importância de ter alguém que os consolassem ou com quem desabafar. Foram mencionados o apoio da terapeuta (pelo único participante que teve este tipo de apoio, naquele momento), da professora, da tia materna (com quem uma das crianças morava), da avó paterna e de amigos da mesma idade. É importante ressaltar que, entre as crianças que se sentiram acolhidas, preponderavam apoios externos ao círculo familiar, com destaque para a presença de amigos de mesma idade. Segundo dois depoimentos:
Eu tenho uma amiga, amiga mesmo, amigona, e eu contava o que eu sentia para ela e ela me dizia que as coisas iam ficar melhor. Falava do primo dela. Com ela eu chorava... até hoje nós somos amigas, mesmo agora que eu estou aqui e ela lá (duas cidades diferentes), a gente se fala sempre. (Fem., 6 anos na época da separação.)

Eu conversava só com o J.. Com ele eu me abria. Eu achava que todo mundo tinha ficado louco. Eu não reconhecia minha mãe... ela tinha ido trabalhar e reclamava o tempo todo, eu não sabia mais o que podia acontecer. $O$ J. sempre contava que com seus pais tinha acontecido a mesma coisa e que depois as coisas iam melhorar tanto... eu acreditava só um pouco nele, mas era o que me segurava quando eu tava explodindo de raiva... ou de medo. A irmã dele também foi legal, sem eles teria sido muito, muito pior. (Masc., 9 anos na época da separação.)

\section{A reorganização da vida familiar}

A reorganização da vida e a realização interna da relação conflito-separação demorou entre dois a quatro anos, segundo o relato dos dez entrevistados que foram capazes de apontar um período de tempo para tal reorganização. Este período coincide com a descrição de Hetherington, Cox e Cox (1982). Quando isso ocorreu, foi possível desenvolver uma relação diferenciada com o pai e a mãe e com o conflito conjugal que os envolveu, expressa pelos jovens como: compreender o porquê da separação e passar a raiva de ambos os pais $(n=3)$; desenvolver uma relação diferenciada com o pai e a mãe $(n=4)$; reaproximar-se da mãe e depois do pai $(n=3)$; reaproximar-se e restabelcer uma relação positiva com o pai $(n=2)$; alienar-se do relacionamento conjugal ou familiar $(n=3)$.

Também foram os próprios entrevistados que identificaram os elementos que, ao longo do tempo, contribuíram ou não para a melhora na qualidade de vida. A redução ou perpetuação do conflito conjugal após a separação, conforme apontado pela literatura (Amato, 1994, 1995; Hetherington \& Stanley-Hagan 1999; Kelly, 1998; Lamb \& cols., 1997; McConnel \& Sim, 1999; Ribeiro, 1989; Souza, 1999; Wadsby $\&$ Svedin, 1994), emergiu como o tema central. Eles consideraram positivo os seguintes aspectos: redução do conflito entre os pais $(n=9)$; estabelecimento de uma relação positiva entre os pais, depois da separação $(n=4)$; compreensão das conseqüências da separação na rotina de vida $(\mathrm{n}=2)$; novas relações conjugais $(n=2)$. Por outro lado, contribuíram negativamente para a qualidade de vida individual e familiar a perpetuação do conflito no sistema de guarda, pensão e visitas $(n=3)$; a superproteção materna ou da família extensa $(n=2)$; e as novas relações conjugais $(n=2)$.

Portanto, a relação com os novos parceiros parentais foi apontada tanto como um aspecto positivo quanto negativo. Embora a presença destes implique em ajustar-se a novos relacionamentos, também traz elementos seguros da irreversibilidade do rompimento parental. As relações foram descritas como inicialmente tensas ou negativas apenas nas três separações descritas pelos filhos como tendo sido causadas por novos relacionamentos amorosos dos pais. Como havia 
sido verificado no estudo anterior de Souza (1998) e de Wagner e Sarriera (1999), as relações com namorados, namoradas, novos cônjuges e suas famílias tenderam a ser consideradas preponderantemente como positivas.

Todos afirmaram que, na verdade, com o passar do tempo, a vida volta ao normal ou então fica diferente, mas fica bem. Há uma recuperação da confiança na previsibilidade da vida e um novo equilíbrio de relacionamentos com os pais, e entre estes, se estabelece. Isto fez com que a unanimidade dos participantes considerassem que, apesar da tristeza inicial, o divórcio foi uma boa solução senão para o conflito parental, ao menos, para o clima familiar.

\section{Considerações finais}

Os relatos espontâneos permitiram reafirmar que a separação é um processo que exige um complexo de adaptações ao longo do tempo, podendo ter um impacto bastante diverso sobre os filhos. O presente estudo teve uma natureza exploratória e qualitativa, buscando compreender a experiência dos filhos durante este processo. Buscamos apenas descrever um conjunto de experiências, sentimentos e reações em sua variabilidade, identificando temas de intervenção, apoio ou orientação e estímulo a futuras pesquisas. Os nossos dados sugerem que é necessário analisar as associações entre a percepção do processo de separação-divórcio e variáveis específicas da família, posição na constelação familiar, nível de conflito envolvido, dentre outros aspectos.

O quadro de sofrimentos múltiplos, descritos pelos entrevistados, e a conclusão de que o divórcio parental acabou sendo um evento positivo, obriga-nos a concordar com Ducibella (1995), no que se refere a assumir uma perspectiva de redução de danos frente a essa realidade. Há muito para ser feito de modo a absorver um pouco das dificuldades infantis e parte significativa diz respeito ao relacionamento entre os pais.

Nossos resultados vão na mesma direção da literatura mundial atual (Amato, 1994, 1995; Hetherington \& StanleyHagan, 1999; Lamb \& cols., 1997; McConnel \& Sim, 1999; Wadsby \& Svedin, 1994), destacando o papel do conflito conjugal como um dos grandes estressores da vida infantil e chamando a atenção dos pesquisadores e clínicos para a necessidade de gerar condições para que a separação e o divórcio realmente permitam a redução do conflito entre os cônjuges, o desenvolvimento de uma relação co-parental positiva e o envolvimento de ambos os pais no cuidado dos filhos. Estas demandas reforçam não só o papel dos trabalhos de mediação familiar, como evidenciam a necessidade de produção de alternativas de orientação de pais, trabalhos de grupos de apoio e produção de literatura popular (Emery, Kitzmann \& Waldron, 1999), procedimentos cada vez mais implementados em todo o mundo ocidental e ainda pouco comuns no Brasil, à despeito de nossa taxa crescente de separações e divórcios.

As informações que os pais fornecem aos filhos, isto é, o que dizem, como e quando, são fundamentais para o proces- so de reorganização da vida familiar. Os relatos sugerem a importância de se dar condições aos pais para trabalharem com o "fechamento em si mesma", por parte da criança, e com a expressão sintomática do sofrimento. Quando os filhos não fazem perguntas, nem sempre compreenderam o que está ocorrendo e acabam estabelecendo um pacto de silêncio com os familiares, evitando, todos, tocar em temas que supõem dolorosos, o que já foi descrito há muito por Wallerstein e Kelly (1980). O mito social de que falar sobre temas dolorosos amplifica o sofrimento precisa ser derrubado. As crianças nem sempre identificam a tensão conjugal, e mesmo quando isto ocorre, não estabelecem, necessariamente, a relação causal conflito-separação. Os pais podem explicar aos filhos os motivos da separação e que esta não os envolve, mas também precisam informar acerca dos aspectos de sua vida que, de fato, se modificarão, dali para a frente. Além disso, precisarão repetir a informação várias vezes e nos diferentes momentos de ajustamento infantil: pré-separação, crise inicial e período de adaptação.

De acordo com os resultados apresentados, as reações negativas iniciais não necessariamente refletem um comprometimento a longo prazo, o que nos faz pensar que estas reações são uma expressão normal da crise. Para os entrevistados, as grandes alterações na rotina de vida e a imprevisibilidade ambiental mostraram ser tão ou mais difíceis que a separação. A crise, provocada pelas mudanças no espaço doméstico e pela menor disponibilidade de relacionamento com um dos genitores, é potencializada pelas mudanças na rotina de vida e na rede social que, se minimizadas, provavelmente reduziriam as dificuldades infantis. Tal demanda conduz novamente à necessidade de se promover a orientação de pais, uma relação co-parental positiva depois da separação e um aprimoramento na comunicação pais-filhos.

Nossos dados sugerem, como foi apontado por Hetherington, Cox e Cox (1982), que decorre um longo período de tempo entre a crise pré-separação e a realização de um novo patamar de funcionamento familiar, isto é, cerca de quatro anos. A identificação de alguns sentimentos e necessidades da criança faz pensar que, à medida que ela consegue alguma previsibilidade de sua vida, aumenta sua capacidade de sentir-se tendo algum controle sobre a situação (Ducibella, 1995). Com isto, ela pode realizar a associação entre o conflito e a separação conjugal, diferenciando-se do mesmo e, por conseqüência, libertar-se para um relacionamento mais positivo com um ou ambos os genitores. Provavelmente, também é este o período de maior risco para a potencialização de distúrbios infantis. Assim, acreditamos ser urgente que os psicólogos clínicos dirijam seus esforços para além da psicoterapia infantil, dedicando-se, também, à geração de propostas mais preventivas e de promoção de saúde, como os grupos de apoio para crianças, mesmo porque este suporte infantil mútuo parece ser aquele que a maioria delas mais se beneficia.

A vivência de solidão e ausência de apoio faz com que o sofrimento e as dificuldades se intensifiquem ainda mais. Schwartz (1992) ressaltou o papel da rede social como fun- 
damental na percepção positiva ou negativa da separação. Se, por um lado, torna-se necessário facilitar aos pais a diferenciação de seus sentimentos relativos à separação e aqueles da criança, também é fundamental permitir-lhes compreender a experiência infantil, suas dificuldades frente às múltiplas mudanças na vida e a importância de contar com a família extensa e, principalmente, com os amigos de mesma idade.

De fato, as particularidades da experiência infantil identificadas descortinam a necessidade de se desenvolver uma "cultura do divórcio", permitindo à sociedade como um todo e, particularmente, aos equipamentos de socialização das crianças como as escolas, creches, e outros, compreenderem o estresse e mudanças de vida pelas quais elas estão passando quando da separação e adaptação à mesma, sem superproteção ou vitimização, mas permitindo-lhes a expressão e elaboração dos sentimentos.

Portanto, fica evidenciada a necessidade de implementação de projetos de pesquisa interdisciplinares, que possibilitem compreender a complexidade do processo de separação ou divórcio e suas implicações para o desenvolvimento da criança e da família. Atenção especial deveria ser dada a investigações que aprofundem a compreensão dos relacionamentos positivos criança-criança, tanto no que se refere à relação entre pares, quanto no que se refere às relações fraternas.

\section{Referências}

Amato, P.P. (1994). Life-span adjustment of children to their parents' divorce. Future of Children, 4, 143-164.

Amato, P.P. (1995). Children's adjustment to divorce: Theories, hypotheses and empirical support. Journal of Marriage and Family, 55, 628-640.

Ducibella, J.S. (1995). Consideration of impact of how children are informed of their parents' divorce decision: A review of literature. Journal of Divorce \& Remarriage, 24, 121-141.

Emery, R.E., Kitzmann, K.M. \& Waldron, M. (1999). Psychological interventions for separeted and divorced families. Em M.E. Hetherington (Org.), Coping with divorce, single parenting and remarriage: A risk and resiliense perspective (pp. 327-345). Hillsdale: Lawrence Erlbaum.

Fry, P.S. (1983). The kid's eye view: The single parent family and children's perceptions of personal needs and concerns for the future. Journal of Child Care, 5, 31-50.
Hetherington, E.M., Cox, M. \& Cox, R. (1982). Effects of divorce on parents and children Em M.E. Lamb. (Org.), Nontraditional families: Parenting and child development (pp. 233-287). Hillsdale: Lawrence Erlbaum.

Hetherington, E.M \& Stanley-Hagan, M. (1999). The adjustment of children with divorced parents: A risk and resiliency perspective. The Journal of Child Psychology and Psychiatry and Allied Disciplines, 40, 129-140.

Kelly, J.B. (1998). Marital conflict, divorce and children's adjustment. Child and Adolescent Psychiatric Clinics of North America, 7, 259-271.

Lamb, M.E., Sternberg, K.J. \& Thompson, R.A. (1997). The effects of divorce and custody arrangments on children's behaviour, development and adjustment. Family and Conciliation Court Review, 35, 393-404.

McConnel, R.A. \& Sim, A.J. (1999). Adjustment to parental divorce: An examination of differences between counselled and non-counselled children. British Journal of Guidance and Counselling, 27, 245-257.

Ribeiro, M.A. (1989). Separação conjugal: o que os filhos acham e como se sentem. Estudos de Psicologia, 2, 25-40.

Schwartz, L.L. (1992). Children's perceptions of divorce. The American Journal of Family Therapy, 20, 324-332.

Souza, R.M. (1998). Família, minha família, a família do papai, uma família sem papai e outros desafios à compreensão infantil. Psicologia Revista, 7, 11-31.

Souza, R.M. (1999). As crianças e suas idéias sobre o divórcio. Psicologia Revista, 9, 33-52.

Wadsby, M. \& Svedin, C.G. (1994). Parental divorce: From the children's viewpoint. Nordic Journal Psychiatry, 48, 107-116.

Wagner, A., Falcke, D. \& Mezza, E.B.D. (1997). Crenças e valores dos adolescentes acerca de família, casamento, separação e projetos de vida Psicologia: Reflexão e Crítica, 10, 155-167.

Wagner, A. \& Sarriera, J.C. (1999). Características do relacionamento dos adolescentes em famílias originais e reconstituídas Em T. Féres-Carneiro (Org.), Casal e família: entre a tradição e a transformação (pp.15-30). Rio de Janeiro: NAU Ed.

Wallerstein, J. \& Kelly, J. (1980). Surviving the break-up. How children and parents cope with divorce. London: Grant McIntyre. 